\title{
Chromium-Induced Nanocrystallization of a-Si Thin Films into the Wurtzite Structure
}

\author{
K. Uma Mahendra Kumar and M. Ghanashyam Krishna \\ School of Physics, University of Hyderabad, Hyderabad-500 046, India \\ Correspondence should be addressed to M. Ghanashyam Krishna, mgksp@uohyd.ernet.in
}

Received 30 October 2007; Accepted 4 February 2008

Recommended by Robert Dorey

Chromium metal-induced nanocrystallization of amorphous silicon (a-Si) thin films is reported. The nanocrystalline nature of these films is confirmed from X-ray diffraction and Raman spectroscopy. Significantly, the deconvolution of Raman spectra reveals that the thin films were crystallized in a mixed phase of cubic diamond and wurzite structure as evidenced by the lines at 512 and $496 \mathrm{~cm}^{-1}$, respectively. The crystallite sizes were between 4 to $8 \mathrm{~nm}$. Optical properties of the crystallized silicon, derived from spectral transmittance curves, revealed high transmission in the region above the band gap. Optical band gap varied between 1.3 to $2.0 \mathrm{eV}$ depending on the nature of crystallinity of these films and remained unaltered with increase in Cr addition from 5 to $30 \%$. This signifies that the electronic structure of the nanocrystalline Silicon films is not affected considerably inspite of the presence of metal silicides and the process of crystallization.

Copyright (c) 2008 K. U. M. Kumar and M. G. Krishna. This is an open access article distributed under the Creative Commons Attribution License, which permits unrestricted use, distribution, and reproduction in any medium, provided the original work is properly cited.

\section{INTRODUCTION}

In recent years, nanocrystalline silicon has found substantial applications in a variety of areas including visible electroluminescent devices [1-3] field-induced ballistic electron emitter [4], thermally induced ultrasonic emitter [5], and biocompatible scaffold [6] to name a few. Nanocrystallization in a-Si has been achieved by different methods starting from solid phase crystallization (SPC) [7], excimer laser annealing [8] and metal induced crystallization (MIC) [9].

Silicon crystallizes in the cubic diamond structure under ambient conditions. However, it is also known to have several polymorphs that are stable only at high pressures. Hexagonal-wurtzite silicon is one such structure and there have been very few reports in literature on its stabilization either in bulk or thin form at ambient pressure and temperature conditions [10]. The Raman spectra of these stabilized structures are studied but very little is known about the optical properties such as transmission, refractive indexand optical band gap of the wurtzite structured Si films.

Chromium-induced nanocrystallization of silicon has been very sparsely reported previously although crystallization induced by metals such as $\mathrm{Al}$ and $\mathrm{Ni}$ has been extensively reported [11-13]. It is known that in many silicides the metal-silicon bond length is very similar to that of Si-Si bond lengths in the wurtzite structure [14]. Furthermore, in the process of metal-induced crystallization of $\mathrm{Si}$, both the metal and metal silicides that form as a consequence of the thermal treatment, act as nucleating agents for the crystallization of Si. The eventual structure of the Si nanocrystals, then, closely mimics that of the metal silicide. The choice of $\mathrm{Cr}$ was, therefore, based on the premise that its silicides under favourable thermodynamic conditions could result in the formation of the wurtzite structure.

The objectives of the present work are therefore to study the possibility of stabilizing the wurtzite structure of Si in thin film form by the metal-induced nanocrystallization route. A further objective is to study the optical properties such as spectral transmission, refractive index, and optical band gap of the wurtzite form of silicon thin films.

\section{EXPERIMENTAL}

Thin films of Cr/a-Si/Borosilicate Glass (BSG) substrate stacks are deposited by resistive thermal evaporation. Silicon thin films were grown by evaporating granular silicon 
powder (99.99\% pure) from a tantalum boat on to BSG substrates. In order to deposit Cr films, Chromium (99.99\% pure), shots were sublimed from a Tantalum boat. The vacuum chamber was evacuated using a diffusion-rotary pump combination equipped with a liquid nitrogen trap to a base pressure of $1 \times 10^{-6}$ Torr. In all cases, the substrate to source distance was kept constant at $8 \mathrm{~cm}$. Relative concentration of metal in the a-Si matrix were varied while varying the a-Si thickness; in the case of $\mathrm{Cr} / \mathrm{a}-\mathrm{Si} / \mathrm{BSG}$ system, the $\mathrm{Cr}$ concentration was varied from $5 \%$ to $30 \%$ by varying the a-Si thin film thickness from $600 \mathrm{~nm}$ to $100 \mathrm{~nm}$. After recording the spectral transmission curves, these films were subjected to thermal annealing. The Cr/a-Si/BSG stacks were annealed at $500^{\circ} \mathrm{C}$ for 20 minutes. The thickness was measured in situ by a quartz crystal monitor and after deposition using a surface profilometer (Model XP-1 Ambios Tech.,USA) and also was calculated from the spectral transmission curves [15]. Before and after annealing, the films was characterized for transmission in the wavelength range 350 to $2500 \mathrm{~nm}$ by means of a dual-beam spectrophotometer (UV-VIS-NIR, Model, Jasco V-570) having a resolution limit of $0.2 \mathrm{~nm}$ and a sampling interval of $2 \mathrm{~nm}$. The transmitted intensities were measured at accuracy better than $0.3 \%$. The refractive indices were extracted from the measured spectral curves by curve fitting using the PUMA code [15]. The Raman spectra were recorded in air using an argon ion laser in the back scattering geometry in a JY-ISA T64000 spectrometer equipped with a confocal microscope and 100X objective ( $1 \mu \mathrm{m}$ diameter focal spot size). Care was taken to optimize the parameters of the laser, so that it does not induce onset of crystallization in the sample. The phase content with in the samples was investigated in a spectral region 200 to $600 \mathrm{~cm}^{-1}$ with an irradiation time of 50 seconds. The Raman spectra presented in this paper are the result of a scan with irradiation duration of 50 seconds. Xray diffraction patterns were recorded on a powder $\mathrm{X}$-ray diffractometer (CPS120 of Inel, France) machine equipped with a Co $\mathrm{K}_{\alpha}=0.178896 \mathrm{~nm}$ and gas phase position sensitive detector.

\section{RESULTS AND DISCUSSION}

\subsection{Morphology and structure}

An optical micrograph of a-Si thin film grown on glass by thermal evaporation is shown in Figure 1(a). The observed microstructures are very familiar features in MBE grown epitaxial silicon thin films and are known as shallow saucer pits (S-pits) [16]. These structures have also been interpreted as point defects or clustered crystallographic imperfections. The silicon thin films shown in these images were X-ray amorphous and hence the saucer pits seen in our samples cannot be due to crystallographic imperfection. The possible reasons for this kind of growth in $\mathrm{MBE}$ grown silicon thin films were attributed to poor vacuum conditions $\left(<10^{-7}\right.$ Torr) and low substrate temperatures during deposition $\left(<700^{\circ} \mathrm{C}\right)$. According to Pearce and McMahon metal contamination will also cause S-pits [17]. In our case, the films were deposited on substrates held at ambient temperature during deposition and in vacuum of $10^{-6}$ Torr and these can be the causes for the formation of the S-pits.

Optical microscopy reveals the morphology of the aSi thin films crystallized by Cr-induced crystallization after annealing at $500^{\circ} \mathrm{C}$ for 20 minutes Figure $1(\mathrm{~b})$. Different kinds of morphologies have been reported earlier in literature for crystalline Si films. Choi et al. reported disklike grains, which grow radially upwards on annealing [18], and Yoon et al. observed dendrite-like growth [19]. After annealing the $\mathrm{Cr} / \mathrm{a}-\mathrm{Si} / \mathrm{BSG}$ stack at $500^{\circ} \mathrm{C}$ in a muffle furnace in ambient atmosphere, the morphology is as shown in Figure 1(b) for a film of thickness of $100 \mathrm{~nm}$ with a $30 \mathrm{~nm}$ of $\mathrm{Cr}$ over the a-Si thin film as a blanket layer and for the film of thickness $280 \mathrm{~nm}$ with the same thickness of Cr overlayer in Figure 1(c). In the latter case, the Si thin film seems to be melted. Cr interaction with a-Si is important since this kind of stack structure is found in a-Si solar cells [20]. In the present study, after melting, due to the density gradients in crystalline silicon and a-Si, ripple formation occurred. These ripple structures are known in laser ablated silicon samples where silicon melting is evidenced [21,22]. Levinson reported columnar structures of $\mathrm{CrSi}_{2}$ in the matrix of $\mathrm{Si}$ [23]. However, in our case the quantity of $\mathrm{CrSi}_{2}$ is very small compared to the a-Si, and therefore these ripples can be attributed to the crystalline Si.

$\mathrm{X}$-ray diffraction patterns of the annealed samples are shown in Figure 2. The unambiguous identification of the presence of crystalline $\mathrm{Si}$ is difficult because there is an overlap with the reflections from the silicides. There are two Bragg reflections at $2 \theta$ values of $78.06^{\circ}$ and $105.33^{\circ}$, which can be indexed as originating either from $\mathrm{Si}$ or $\mathrm{CrSi}_{2}$. To remove the ambiguity, Raman scattering experiments were carried out in both cases and results are presented in the next section. However, crystallite size determination from FWHM shows that the films are nanocrystalline with an average crystallite size of $6 \pm 1 \mathrm{~nm}$.

\subsection{Raman spectroscopy}

The Raman spectrum of a $100 \mathrm{~nm}$ thick a-Si film on glass substrate is shown in Figure 3. A broad feature centered at $472 \mathrm{~cm}^{-1}$ was observed. After correcting for the base line, a Voigt-like function was used to curve fit the Raman spectra. The curve fitting reveals that the Raman signal between 400 and $560 \mathrm{~cm}^{-1}$ is comprised of two resonances, one peak centered at $472 \mathrm{~cm}^{-1}$ which is attributed to the amorphous silicon, while the peak at $504 \mathrm{~cm}^{-1}$ is due to nanocrystalline cubic silicon. Using the $\mathrm{Zi}$ model, the derived crystallite size was estimated $\sim 2 \pm 0.5 \mathrm{~nm}$ size [24]. However, since these films were X-ray amorphous, the values may not be entirely accurate.

In our studies, the relative concentration of $\mathrm{Cr}$ metal was varied from $30 \%$ to $5 \%$ by varying the a-Si film thickness from $100 \mathrm{~nm}$ to $600 \mathrm{~nm}$. After annealing the Cr/a-Si/BSG stack at $500^{\circ} \mathrm{C}$ for 20 minutes, crystallization of a-Si started. The Raman shift of the $30 \%$ chromium doped a-Si thin films after annealing is shown in Figure 4. The spectral components are deconvoluted into four parts that belong to (a) amorphous silicon $\left(468 \mathrm{~cm}^{-1}\right)$, (b) hexagonal silicon 


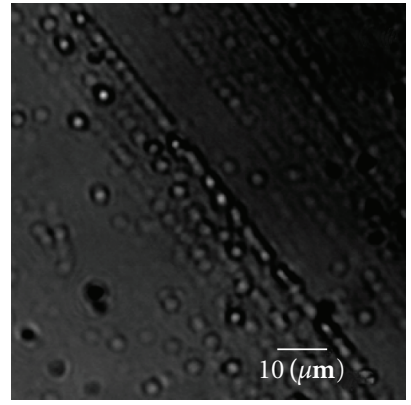

(a)

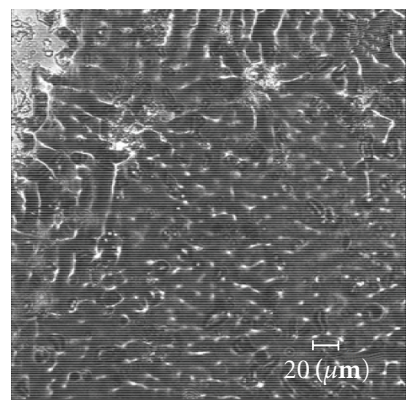

(b)

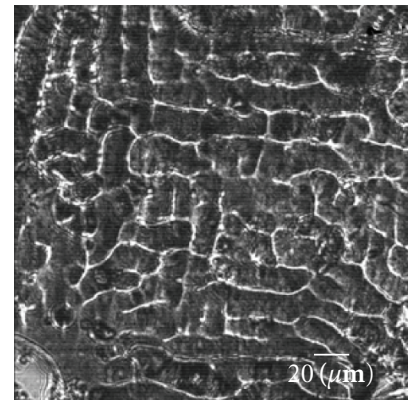

(c)

FIGURE 1: Optical micrograph of (a) a-Si thin film on BSG substrates showing shallow saucer pits (S-pits). (b) Cr/a-Si/BSG after annealing at $500^{\circ} \mathrm{C}$ for 20 minutes. (c) $280 \mathrm{~nm}$ thick a-Si film with $30 \mathrm{~nm}$ of $\mathrm{Cr}$ overlayer annealed at $500^{\circ} \mathrm{C}$ for 20 minutes.

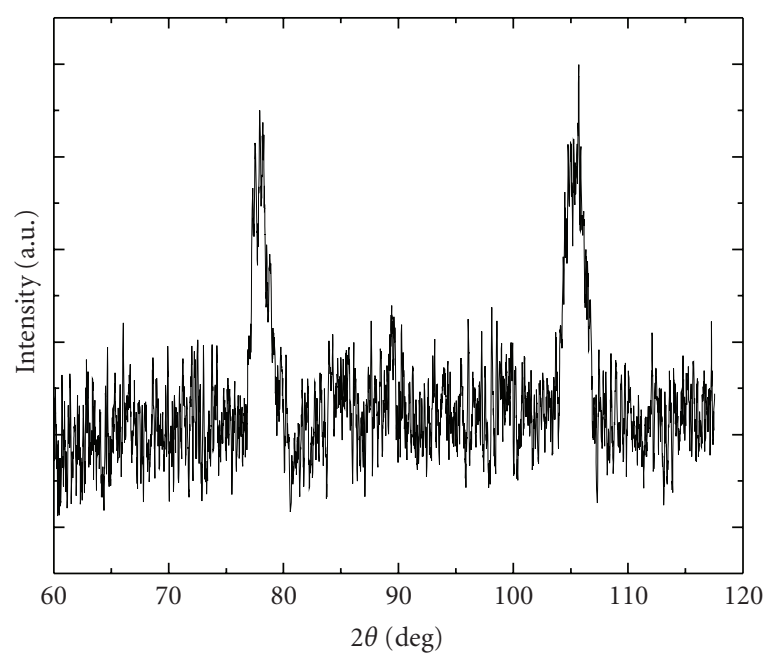

FIGURE 2: X-ray diffraction pattern of $\mathrm{Cr} / \mathrm{a}-\mathrm{Si} / \mathrm{BSG}$ after annealing at $500^{\circ} \mathrm{C}$ for 20 minutes.

$\left(496 \mathrm{~cm}^{-1}\right)$, (c) cubic silicon $\left(512 \mathrm{~cm}^{-1}\right)$, and (d) $\mathrm{Cr}_{2} \mathrm{O}_{3}$ $\left(548 \mathrm{~cm}^{-1}\right)$. Once the concentration of $\mathrm{Cr}$ was decreased to $5 \%$, the silicon started crystallizing in wurzite structure. The Raman shift of the wurzite silicon is shown in Figure 5. The presence of the wurtzite structure, in the current case, is confirmed by the prominent $\Gamma_{5}^{\prime}$ resonance peak at $496 \mathrm{~cm}^{-1}$. However, the theoretically predicted resonance peak is at $498 \mathrm{~cm}^{-1}$ [25]. The downward shift of $2 \mathrm{~cm}^{-1}$ can be attributed to the strain or small crystallite size of wurzite silicon. The peak at $548 \mathrm{~cm}^{-1}$ belongs to $\mathrm{Cr}_{2} \mathrm{O}_{3}$ (Oxide formation is not avoidable in a furnace working in ambient atmosphere). Metal silicide $\left(\mathrm{CrSi}_{2}\right)$ peaks at 307 and $350 \mathrm{~cm}^{-1}$ are also observed in the low-frequency part of the Raman spectra shown in the inset of Figure 4. The presence of $\mathrm{Cr}_{2} \mathrm{O}_{3}$, from the Raman spectra, indicates surface oxidation of the films. This would also suggest the possibility of some $\mathrm{SiO}_{\mathrm{x}}$ phase being present in the films. However, it is difficult to unambiguously establish this since the thin films are grown on borosilicate glass substrates. Similarly, distinguishing $\mathrm{SiO}_{\mathrm{x}}$ from films and substrate would be difficult using FTIR. Hence, while the presence of $\mathrm{SiO}_{\mathrm{x}}$ in

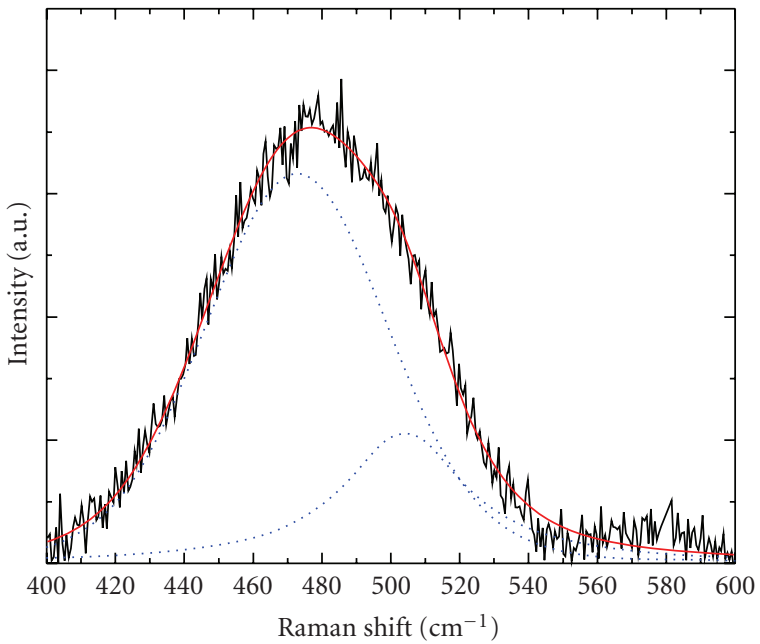

Figure 3: Raman shift of as deposited a-Si thin film on glass.

the films cannot be ruled out, its presence cannot also be unambiguously established in the current case.

Wurzite silicon has three vibrational peaks corresponding to the two vibrations in the plane of hexagonal layers and one perpendicular to these layers [25]. Zhang et al. have reported wurzite silicon by laser ablation [26], and they observed Raman peaks at 516 and $518 \mathrm{~cm}^{-1}$ due to the hexagonal silicon. In contrast, our investigations indicate that the Si films crystallize in the mixed structure at high $\mathrm{Cr}$ concentrations and in the wurzite structure at low $\mathrm{Cr}$ concentrations. A survey of the structures of $\mathrm{Cr}_{2} \mathrm{O}_{3}$ and $\mathrm{CrSi}_{2}$ reveals that $\mathrm{Cr}_{2} \mathrm{O}_{3}$ exists in the corundum structure with a space group $\mathrm{R} \overline{3} \mathrm{c}$ with six formula units in the hexagonal unit cell. The metal ions are located in special positions along the threefold axis at $\pm[00 \mathrm{z} ; 00(1 / 2)+\mathrm{z}]$ and the oxygens lie on diads at $\pm[\mathrm{x} 0(1 / 4) ; 0 \mathrm{x}(1 / 4) ;(1 / 4)][27]$ and in the case of $\mathrm{CrSi}_{2}$, they have three formula units per hexagonal unit cell. Its lattice parameters are $\mathrm{a}=4.431 \AA$ and $\mathrm{c}=6.354 \AA$ [28]. It is, therefore, clear that the silicide and the oxide both exist in the hexagonal form and are structurally isomorphous to the hexagonal form of $\mathrm{Si}$. As a consequence, they act as 


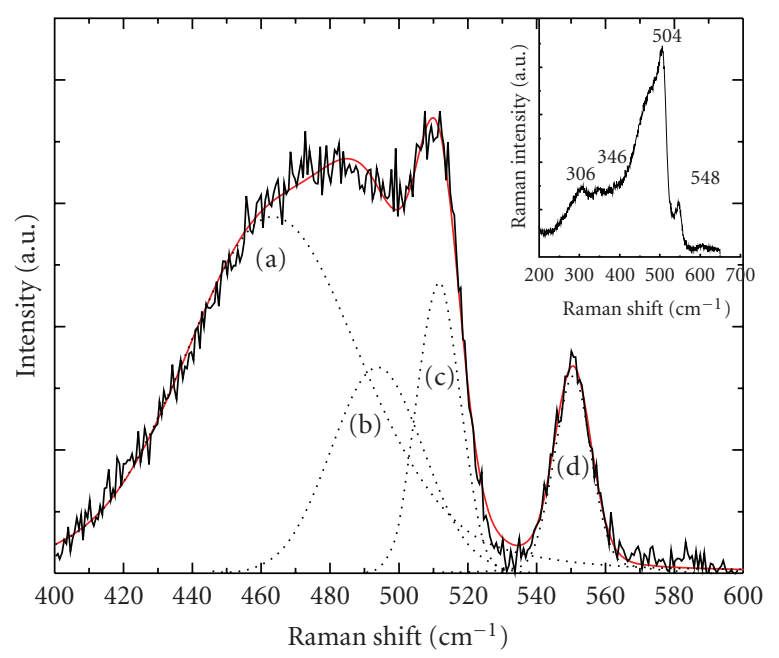

Figure 4: The Raman spectral components are deconvoluted into four parts that belong to (a) amorphous Silicon, (b) hexagonal Silicon, (c) cubic Silicon, and (d) $\mathrm{Cr}_{2} \mathrm{O}_{3}$.

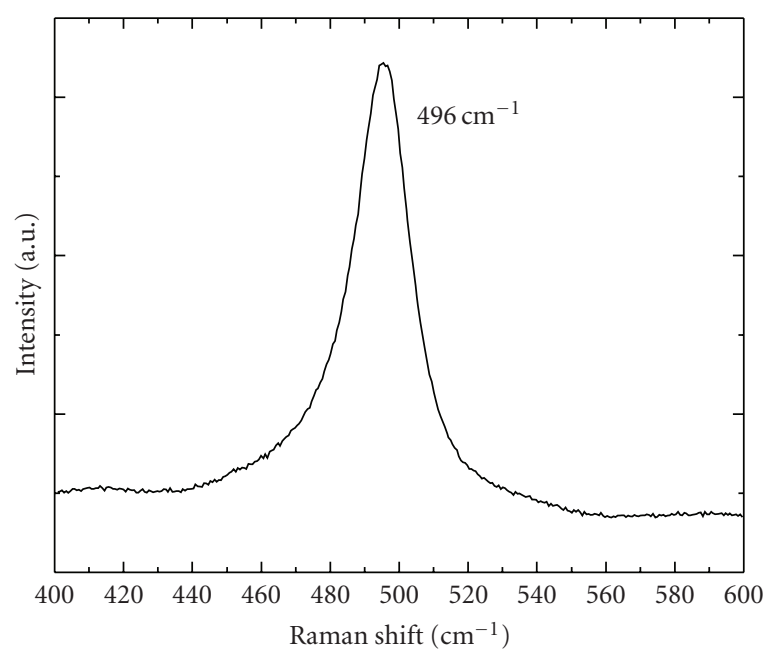

FIgURE 5: The Raman shift of the wurzite silicon centered at $496 \mathrm{~cm}^{-1}$ due to $\Gamma_{5}^{\prime}$ resonances.

seeds for the formation of the hexagonal-wurtzite structure of silicon in the crystallization process. To the best of our knowledge, this is the first experimental evidence of metalinduced wurzite structure crystallization of Si.

\subsection{Optical properties}

The spectral transmittance of the $100 \mathrm{~nm}$ pure a-Si thin film is shown in Figure 6(a). The spectral transmittance of this film with a $30 \mathrm{~nm}$ Cr thin film blanket is shown in Figure 6(b) and the stack of these films after annealing at $500^{\circ} \mathrm{C}$ for 20 minutes is shown in Figure 6(c). The lower transmittance prior to annealing is due to the blanket of $\mathrm{Cr}$ metal film on top of the a-Si. After annealing, the increase in the transmittance, to $80 \%$, is a combined effect

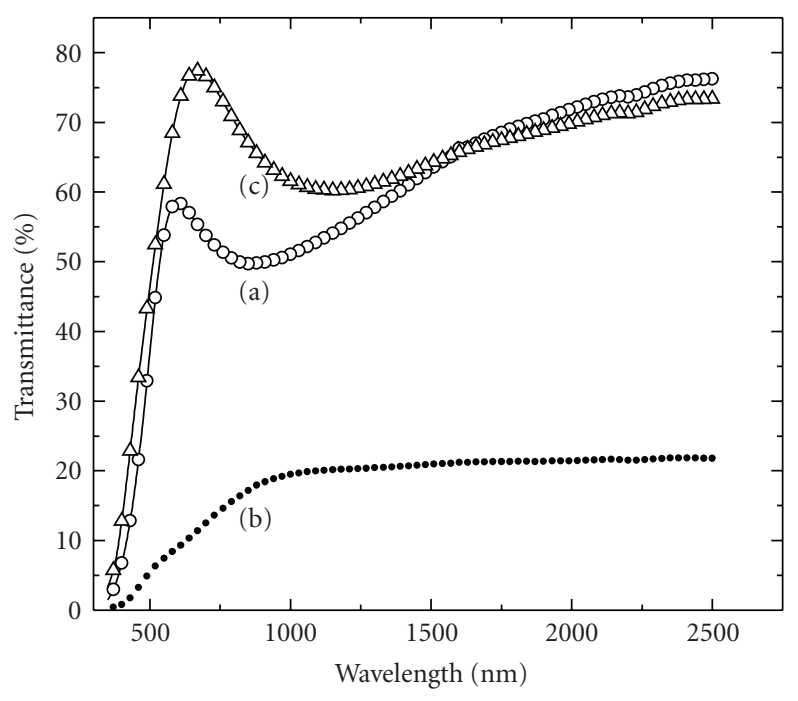

FIGURE 6: The spectral transmittance of the (a) $100 \mathrm{~nm}$ pure a-Si thin film, (b) a-Si film with a $30 \mathrm{~nm}$ Cr thin film blanket, and (c) after annealing at $500^{\circ} \mathrm{C}$ for 20 minutes.

of formation of different phases in the Cr/a-Si stack. It may be noted that Raman spectroscopy revealed the presence of $\mathrm{Cr}_{2} \mathrm{O}_{3}$, after annealing in ambient atmosphere. Apart from these oxide compounds the formation of $\mathrm{CrSi}_{2}$ was also in evidence. $\mathrm{CrSi}_{2}$ is intrinsically a semiconductor with a band gap of $0.35 \mathrm{eV}$ [28], but the observed absorption edge as estimated from the value at which the spectral transmittance falls to $20 \%$ is much higher. The actual calculated values are discussed below. From the spectral transmittance curves another important optical property, refractive index, can also be extracted. The index of refraction is sensitive to the coordination chemistry and composition around Si. In the present study, as mentioned earlier, after annealing, different compounds with varying concentrations are found in the volume of the sample and also on the surface. This has immense effect on the thin film refractive index. The refractive index behaviour before (open circles) and after annealing (closed circles), as function of wavelength, in Figure 7 shows that the values varied from 2.7 to 2.5 at $1100 \mathrm{~nm}$ of wavelength for the film of thickness $100 \mathrm{~nm}$ whereas the bulk silicon value is 3.4.

The optical band gap (Tauc gap) is determined from the extrapolation of linear part in the $(\alpha \mathrm{h} v)^{1 / 2} \mathrm{Vs} \mathrm{h} v$ plot assuming an indirect band gap. The band gap variation with the thickness of the a-Si thin films before and after annealing is shown in Figure 8. It is observed that the band gap varied from $2 \mathrm{eV}$ for the $100 \mathrm{~nm}$ thick film to $1.3 \mathrm{eV}$ for the film of thickness $600 \mathrm{~nm}$. It is interesting that the optical absorption edge of the as-deposited a-Si thin film and the film after annealing with a $30 \mathrm{~nm}$ Cr layer on the top remained unaltered. The edge, in contrast, shifted towards lower energies for the Cr/a-Si/BSG stack before annealing. This small red shift in the absorption edge could be due to the formation of metal silicide during deposition. The absorption edge, which represents the electronic band structure of the materials, remained almost unaltered after annealing. 


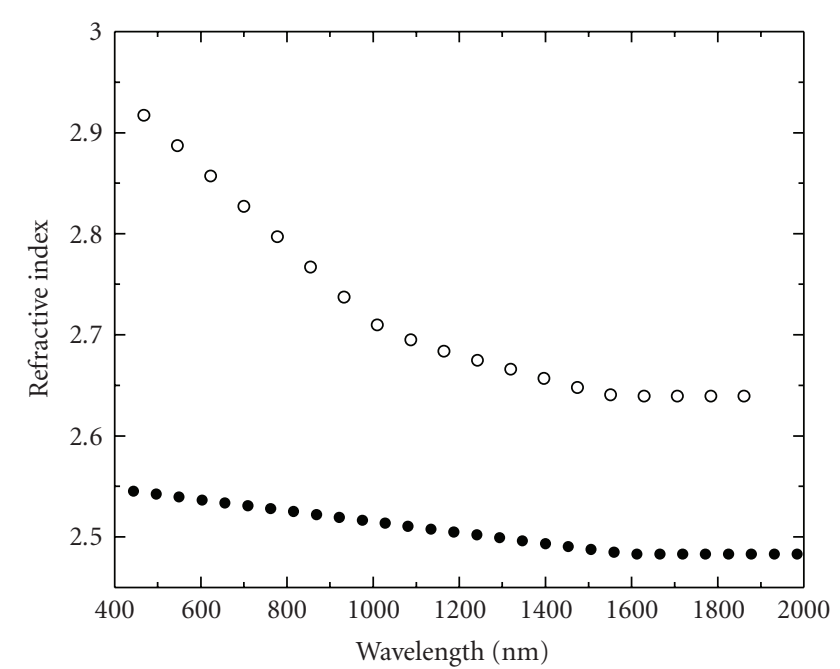

FIgURE 7: The refractive index behaviour of a $100 \mathrm{~nm}$ Si thin film as function of wavelength; open circles represent pure a-Si thin film and closed circles represent the annealed film with a $30 \mathrm{~nm} \mathrm{Cr}$ thin film blanket.

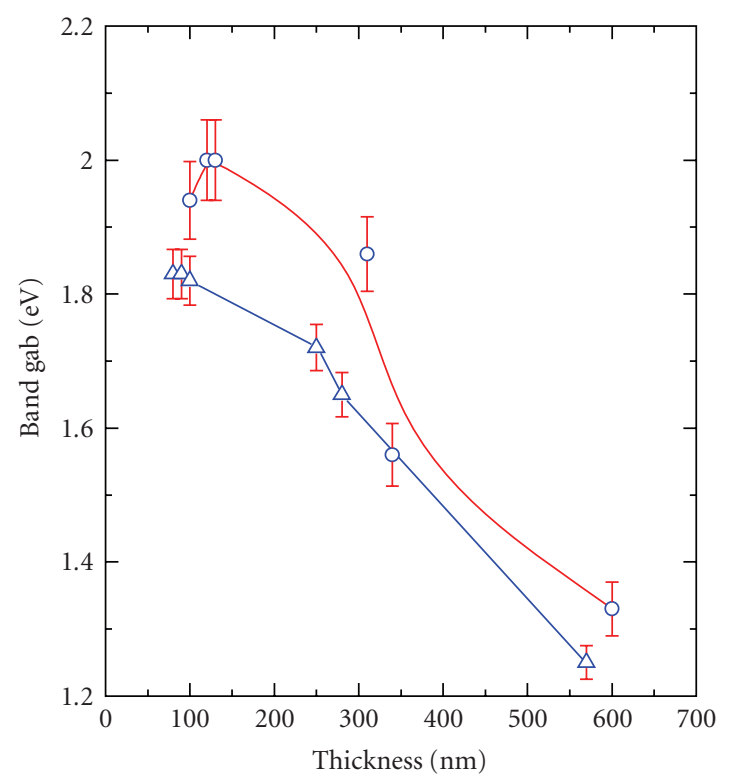

FIgURE 8: The band gap variation as function of thickness for the (open triangles) as deposited pure a-Si films (closed circles) after annealing.

This signifies the fact that the different compounds observed during the annealing process do not disturb or affect the essential optical properties of a-Si. We believe this to be a very important observation for several optical applications relying on nanocrystalline-Si.

\section{CONCLUSIONS}

The stabilization of wurtzite structure of silicon via metalinduced nanocrystallization is demonstrated. The identi- fication of the crystalline phase was done using Raman spectroscopy and $\mathrm{x}$-ray diffraction. The optical properties of the nanocrystalline silicon thin films are characterized by high transmittance, a lower refractive index than bulk diamond-like $\mathrm{Si}$ but a larger optical band gap. The presence of $\mathrm{CrSi}_{2}$ and $\mathrm{Cr}_{2} \mathrm{O}_{3}$ seems to trigger the formation of the wurtzite structure.

\section{ACKNOWLEDGMENTS}

The authors acknowledge the financial support from the DST-ITPAR Program. K. U. M. Kumar would like to thank the DST-ITPAR for providing a Bose-Romagnosi fellowship to do this work. Facilities provided by the UGC under UPE and SAP Programs are gratefully acknowledged. The authors wish to thank Dr. Vasant Sathe, UGC-DAE CSR, Indore centre, for the invaluable help in Raman spectroscopy measurements.

\section{REFERENCES}

[1] J. Huo, R. Solanki, J. L. Freeouf, and J. R. Carruthers, "Electroluminescence from silicon nanowires," Nanotechnology, vol. 15, no. 12, pp. 1848-1850, 2004.

[2] W. Jantsch, S. Lanzerstorfer, L. Palmetshofer, M. Stepikhova, and H. Preier, "Different Er centres in Si and their use for electroluminescent devices," Journal of Luminescence, vol. 80, no. 1-4, pp. 9-17, 1998.

[3] T. A. Burr, A. A. Seraphin, E. Werwa, and K. D. Kolenbrander, "Carrier transport in thin films of silicon nanoparticles," Physical Review B, vol. 56, no. 8, pp. 4818-4824, 1997.

[4] N. Koshida, T. Ohta, and B. Gelloz, "Operation of nanosilicon ballistic electron emitter in liquid water and hydrogen generation effect," Applied Physics Letters, vol. 90, no. 16, Article ID 163505, 2007.

[5] H. Shinoda, T. Nakajima, K. Ueno, and N. Koshida, "Thermally induced ultrasonic emission from porous silicon," Nature, vol. 400, no. 6747, pp. 853-855, 1999.

[6] W. Sun, J. E. Puzas, T.-J. Sheu, and P. M. Fauchet, "Porous silicon as a cell interface for bone tissue engineering," Physica Status Solidi (A), vol. 204, no. 5, pp. 1429-1433, 2007.

[7] S. Holgado, J. Martínez, J. Garrido, C. Morant, and J. Piqueras, "Rapid solid phase crystallization of nanocrystalline silicon deposited by electron cyclotron plasma chemical vapor deposition," Applied Physics Letters, vol. 69, no. 13, pp. 1873$1875,1996$.

[8] J. C. Bean, H. J. Leamy, J. M. Poate, et al., "Epitaxial laser crystallization of thin-film amorphous silicon," Applied Physics Letters, vol. 33, no. 3, pp. 227-230, 1978.

[9] K. U. M. Kumar, R. Brahma, M. G. Krishna, A. K. Bhatnagar, and G. Dalba, "An optical study of Ni induced crystallization of a-Si thin films," Journal of Physics: Condensed Matter, vol. 19, no. 49, Article ID 496208, 11 pages, 2007.

[10] J. Bandet, B. Despax, and M. Caumont, "Vibrational and electronic properties of stabilized wurtzite-like silicon," Journal of Physics D, vol. 35, no. 3, pp. 234-239, 2002.

[11] J.-H. Shim, S. Im, Y. J. Kim, and N.-H. Cho, "Nanostructural and optical features of hydrogenated nanocrystalline silicon films prepared by aluminium-induced crystallization," Thin Solid Films, vol. 503, no. 1-2, pp. 55-59, 2006. 
[12] L. R. Muniz, C. T. M. Ribeiro, A. R. Zanatta, and I. Chambouleyron, "Aluminium-induced nanocrystalline Ge formation at low temperatures," Journal of Physics: Condensed Matter, vol. 19, no. 7, 2007.

[13] C. Hayzelden and J. L. Batstone, "Silicide formation and silicide-mediated crystallization of nickel-implanted amorphous silicon thin films," Journal of Applied Physics, vol. 73, no. 12, pp. 8279-8289, 1993.

[14] A. F. Wells, Structural Inorganic Chemistry, Oxford University Press, Oxford, UK, 4th edition, 1975.

[15] E. G. Birgin, I. Chambouleyron, and J. M. Martínez, "Estimation of the optical constants and the thickness of thin films using unconstrained optimization," Journal of Computational Physics, vol. 151, no. 2, pp. 862-880, 1999.

[16] D. Pomerantz, "A cause and cure of stacking faults in silicon epitaxial layers," Journal of Applied Physics, vol. 38, no. 13, pp. 5020-5026, 1967.

[17] C. W. Pearce and R. G. McMahon, "Role of metallic contamination in the formation of "saucer" pit defects in epitaxial silicon," Journal of Vacuum Science and Technology, vol. 14, no. 1, pp. 40-43, 1977.

[18] J. H. Choi, D. Y. Kim, S. S. Kim, S. J. Park, and J. Jang, "Polycrystalline silicon prepared by metal induced crystallization," Thin Solid Films, vol. 440, no. 1-2, pp. 1-4, 2003.

[19] S. Y. Yoon, S. J. Park, K. H. Kim, and J. Jang, "Metalinduced crystallization of amorphous silicon," Thin Solid Films, vol. 383, no. 1-2, pp. 34-38, 2001.

[20] B. G. Yacobi, A. J. Szadkowski, S. Zukotynski, and J. M. Corbett, "Compound formation between amorphous silicon and chromium," Journal of Applied Physics, vol. 51, no. 12, pp. 6424-6425, 1980.

[21] J. S. Preston, H. M. van Driel, and J. E. Sipe, "Order-disorder transitions in the melt morphology of laser-irradiated silicon," Physical Review Letters, vol. 58, no. 1, pp. 69-72, 1987.

[22] M. A. Bösch and R. A. Lemons, "Laser-induced melt dynamics of Si and silica," Physical Review Letters, vol. 47, no. 16, pp. 1151-1155, 1981.

[23] L. M. Levinson, "Highly anisotropic columnar structures in silicon," Applied Physics Letters, vol. 21, no. 6, pp. 289-291, 1972.

[24] J. Zi, H. Buscher, C. Falter, W. Ludwig, K. Zhang, and X. Xie, "Raman shifts in Si nanocrystals," Applied Physics Letters, vol. 69, no. 2, pp. 200-202, 1996.

[25] R. J. Kobliska and S. A. Solin, "Raman spectrum of wurtzite silicon," Physical Review B, vol. 8, no. 8, pp. 3799-3802, 1973.

[26] Y. Zhang, Z. Iqbal, S. Vijayalakshmi, and H. Grebel, "Stable hexagonal-wurtzite silicon phase by laser ablation," Applied Physics Letters, vol. 75, no. 18, pp. 2758-2760, 1999.

[27] R. E. Newnham and Y. M. Dehaan, "Refinement of the a A1203, Ti203, V203 and Cr203 structures," Zeitschrift für Kristallographie: New Crystal Structures, vol. 117, p. 235, 1962.

[28] M. C. Bost and J. E. Mahan, "An investigation of the optical constants and band gap of chromium disilicide," Journal of Applied Physics, vol. 63, no. 3, pp. 839-844, 1988. 

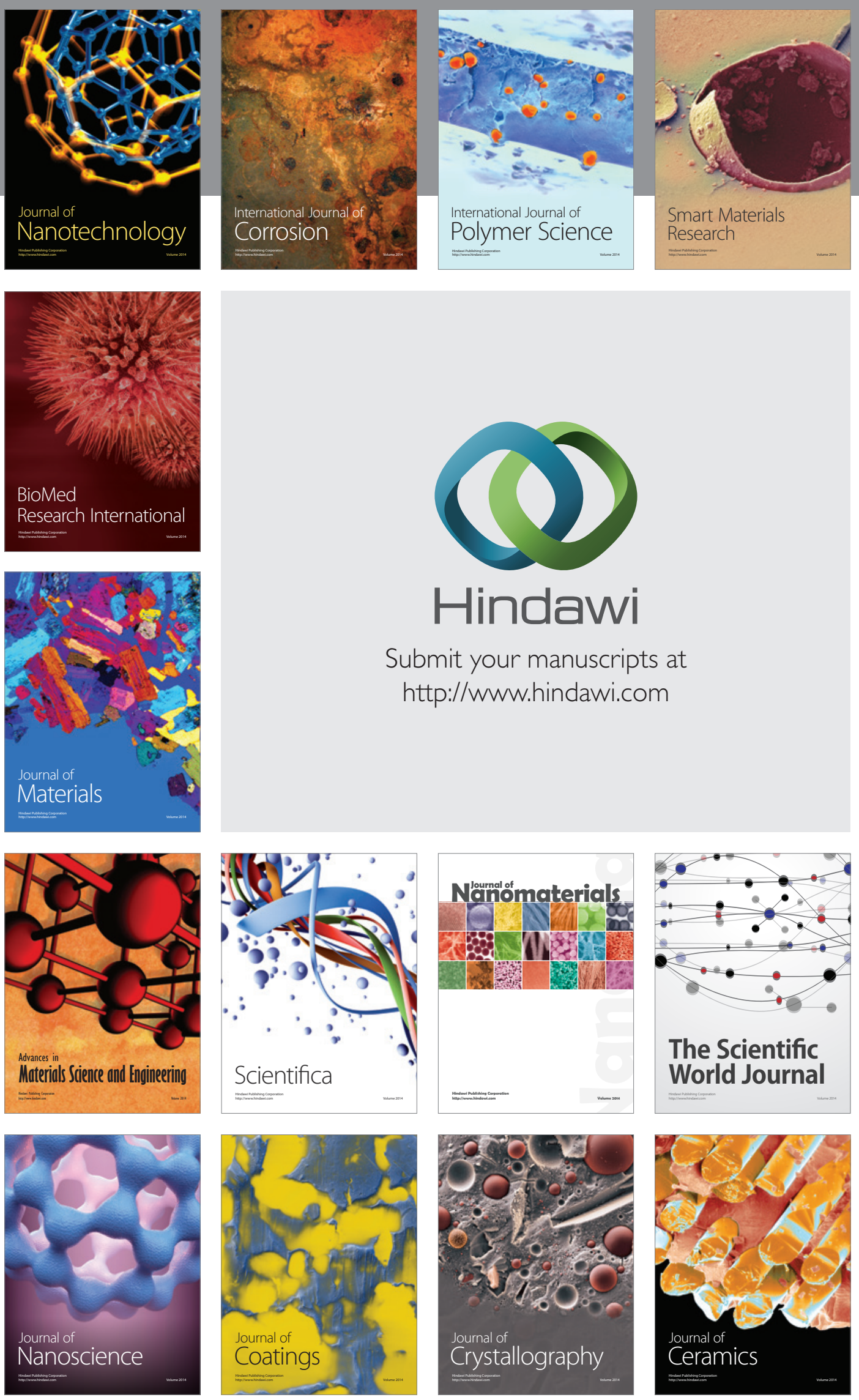

The Scientific World Journal

Submit your manuscripts at

http://www.hindawi.com

\section{World Journal}

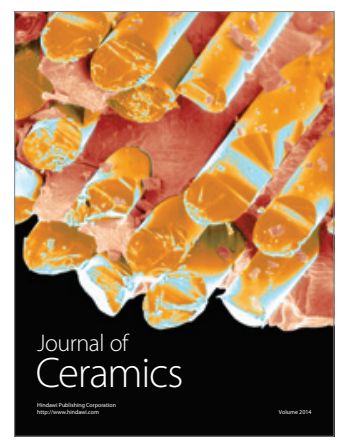

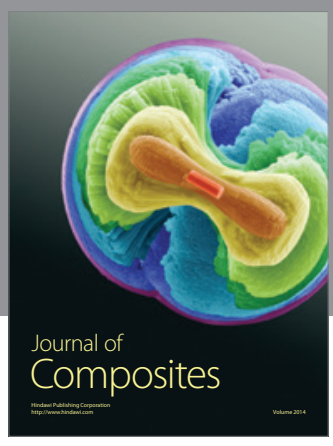
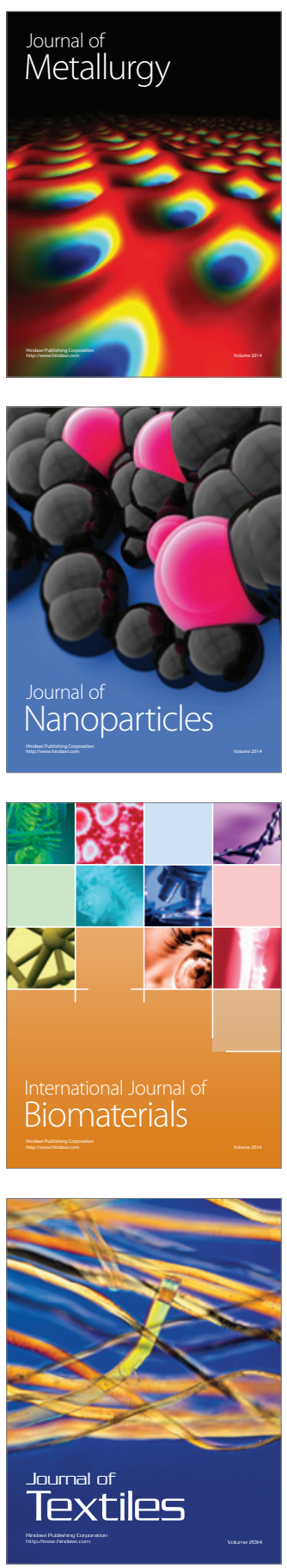